Marquette University

e-Publications@Marquette

Psychology Faculty Research and Publications

Psychology, Department of

$10-1-2010$

Exploring the Role of Attachment Style in the Relation between Family Aggression and Abuse in Adolescent Dating Relationships

John H. Grych

Marquette University, john.grych@marquette.edu

Kristen M. Kinsfogel

Marquette University

Accepted version. Journal of Aggression, Maltreatment and Trauma, Vol. 19 (Fall 2010), DOI:

10.1080/10926771.2010.502068. Used with permission. (C) 2010 Taylor \& Francis. 


\section{Exploring the Role of Attachment Style in the Relation between Family Aggression and Abuse in Adolescent Dating Relationships}

By John H. Grych and Kristen M. Kinsfogel

This study investigated romantic attachment style as a potential moderator of the link between family aggression and dating aggression, and examined its relations with documented mediators of the impact of interparental conflict on dating behavior: attitudes about the justifiability of aggression and anger regulation. Participants were 391 ethnically diverse 14-to 18-year-olds (52\% female). Attachment style was a significant moderator for boys and girls, but the pattern of results differed by gender. In general, attachment anxiety was a more consistent predictor than avoidance of boys' dating aggression, cognitions, and emotions, whereas anxiety and avoidance both acted as significant moderators for girls. These results suggest that youths' romantic attachment style can amplify or attenuate the impact of family aggression on abusive behavior in dating relationships by influencing their beliefs about the acceptability of aggression and their ability to regulate anger.

Establishing satisfying relationships with peers and dating partners is a critical developmental task in adolescence. Because these relationships can establish patterns for forming and maintaining intimate relationships in adulthood, understanding how teens develop healthy or unhealthy romantic relationships has important implications for later interpersonal functioning and mental health. Further, identifying factors that give rise to coercive, controlling, and abusive behavior in romantic relationships provides an empirical basis for developing effective approaches to preventing intimate partner violence (see Kerig, Volz, Arnzen Moeddel, \& Cuellar, this issue).

One consistent predictor of adolescents' abusive behavior toward dating partners is exposure to aggression in the family, especially for boys(for reviews, see O'Leary \& Cascardi, 1998;Wekerle \& Wolfe, 1999). Both experiencing parental maltreatment and witnessing verbal and physical aggression between parents increase the likelihood that adolescents will engage in coercive, abusive, or violent behavior when they begin dating. Moreover, several processes that might explain how these family experiences lead to aggression in romantic relationships have been identified (Wekerle \& Wolfe, 1999), including attitudes about the justifiability of aggression, emotional regulation, and affiliation with aggressive or antisocial peers(e.g., Connolly, Friedlander, Pepler, Craig, \& Laporte, 2010; Kinsfogel \& Grych, 2004; Riggs \& O'Leary, 1996).

Of course, not all youths exposed to interparental aggression or child maltreatment are 
abusive toward their dating partners, but there is little theory or data to explain when continuity from the family to romantic relationships would be expected and when it would not. Consequently, a critical next step in the development of conceptual models of dating aggression is to identify factors that increase or decrease the risk that aggression in the family will lead to aggression in dating relationships. Because there is an indefinite number of constructs that could play a moderating role, the effort to understand these processes will be most efficient and effective if it is guided by theory. Given its emphasis on behavior and affect in intimate relationships, attachment theory has much to offer in building conceptual models of how abuse and coercion can arise in adolescent dating relationships. Attachment theory holds that individuals develop working models, or expectations about the availability, reliability, and responsivity of caregivers, and that these working models influence the way that people perceive and respond to others in close relationships (Bowlby, 1969), including romantic relationships in adolescence and adulthood (e.g., Collins \& Sroufe, 1999; Fraley \& Shaver, 2000; Hazan \& Shaver, 1994). Although parent-child relationships are presumed to have the strongest influence on the development of children's working models, children's observations of their parents' marital relationship also appear to shape young children's beliefs and expectations about relationships (Grych, Wachsmuth-Schlaefer, \& Klockow, 2002; Shamir, Schudlich, \& Cummings, 2001; Waters \& Cummings, 2000).

There are different approaches to conceptualizing and measuring attachment in adolescence. Historically, children's attachment quality with their parents has been classified into discrete categories (secure, anxious-ambivalent, anxious-avoidant, disorganized), and some studies of adolescents have adopted the same approach. However, there is compelling evidence that working models for romantic relationships are better represented along two orthogonal dimensions - anxiety and avoidance — than by categories (see Brennan, Clark, \& Shaver, 1998; Fraley \& Waller, 1998). The anxiety dimension reflects the extent to which individuals monitor and appraise events relevant to attachment-related goals (Fraley \& Shaver, 2000). Highly anxious people are uncertain that their partners will be available to them and are hypervigilant in their monitoring of cues that could indicate problems in the relationship. In contrast, those low in anxiety are more trusting and confident that their partners will be available when needed and consequently less motivated to scan the environment for threats to the relationship. Avoidance pertains to the regulation of behavior relevant to attachment goals (Fraley \& Shaver, 2000).Highly avoidant people tend to resist becoming too close to their partner and investing too much in the relationship, whereas those low in avoidance are comfortable with emotional intimacy and interdependence. 
Initial studies suggest that attachment style is related to aspects of dating relationships in adolescence (e.g., Davila, Steinberg, Kachadourian, Cobb, \& Fincham, 2004; Furman, Simon, Shaffer, \& Bouchey, 2002; Steinberg, Davila, \& Fincham, 2006). For example, a recent study by Steinberg et al. (2006) found that adolescents' attachment quality with their parents predicted their expectations about the success and satisfaction of their future marital relationship and their experiences with dating (e.g., being turned down for a date, having been coerced into sex, dating someone in another relationship). Further, attachment partially mediated links between inter-parental conflict and these aspects of dating relationships. In contrast, findings from research examining attachment style as a predictor or mediator of aggression toward dating partners have been inconsistent. Whereas attachment style has been linked to men's aggression toward their wives (e.g., Holtzworth-Monroe, Stuart, \& Hutchinson, 1997), studies examining attachment style in adolescence indicate that attachment insecurity per se does not directly predict aggression in dating relationships (Feiring, Deblinger, Hoch-Espada, \& Haworth, 2002; Levendosky, Huth-Bocks, \& Semel, 2002).

Rather than conceptualizing attachment as a mediator, Wekerle and Wolfe (1998) examined the idea that attachment style moderates the effect of family aggression on dating behavior. That is, they proposed that the relation between aggression in the two contexts differs depending on the quality of adolescents' attachment. The findings supported this hypothesis: Child maltreatment was more closely related to abusive behavior in dating relationships for boys reporting either avoidant or ambivalent attachment styles than for those who were securely attached. Anxious-ambivalent boys who were maltreated also were more likely to be victims of dating abuse than those with more secure attachment styles. However, this study did not examine the mechanism by which attachment style increases or decreases the risk of dating aggression; consequently, it is not clear why youths with insecure attachment are more likely to perpetrate or be the victim of abusive behavior in romantic relationships.

The goal of this study was to further investigate the potential moderating effect of attachment style by examining how it relates to processes shown to mediate the association between family aggression and abusive behavior in romantic relationships. Specifically, we focused on adolescents' attitudes about aggression in relationships and their emotion regulation, both of which appear to be mechanisms through which experiences with high levels of interparental conflict and maltreatment lead to aggression toward dating partners (e.g., Foo \& Margolin, 1995; Kinsfogel \& Grych, 2004; Riggs \& O'Leary, 1996). We tested the hypothesis that the strength of the association between youths' attitudes about aggression and capacity to regulate anger and their experiences in romantic relationships depends on their working models 
of intimate relationships. Adolescents who view aggressive behavior as justifiable in dating relationships might be more likely to act on aggressive impulses if they are fearful about the status of their relationship. Highly anxious adolescents tend to overreact to or misinterpret "cues" that their relationship is threatened, and those with more accepting attitudes about aggression might respond to these perceptions by trying to control and coerce their dating partners. Highly avoidant individuals also might be more likely to act on aggressive impulses, but for different reasons. Their tendency to disengage emotionally might undermine the empathy and concern that might otherwise inhibit teens from mistreating their boyfriends or girlfriends, and those who view aggression as more justifiable might be less motivated to control aggressive impulses to preserve the relationship. Similarly, difficulties regulating emotion, especially anger, might be more likely to result in aggression in youths who are anxious about the status of their relationship or are seeking greater distance from their dating partner.

We first examined whether adolescents' reports of anxiety and avoidance in romantic relationships moderated the association between family aggression and hostile, abusive behavior toward dating partners. Most prior studies assessed youths' attachment to their parents, which is expected to shape their working models in regard to dating relationships; however, the expectations that youths have toward dating partners also are likely to be influenced by their experiences in peer relationships, including their initial experiences with dating. Consequently, we assessed adolescents' working models in relation to dating relationships because they might have a more proximal effect on behavior in romantic relationships.

We then explored the role that attachment style in romantic relationships might play in fostering dating aggression by examining its associations with factors found to mediate the link between family aggression and dating aggression. In an earlier analysis of these data, Kinsfogel and Grych (2004) reported that boys' attitudes about the justifiability of aggression and difficulty regulating anger uniquely and independently mediated the association between conflict in the family and abusive behavior in their romantic relationships. Interparental aggression was not correlated with dating aggression for girls, and so mediational models were not tested in that study. Given those differences, and other reports of gender differences in the relations between aggression in the family and in romantic relationships, we examined whether the proposed moderating processes operated similarly for boys and girls.

\section{Method}

The sample consisted of 391 14-to 18-year-old high school students (52\% girls; $M$ age = $15.6, S D=1.1$ years), diverse in terms of both ethnicity (56\% Anglo American, $21 \%$ Latino, 13\% 
African American, and 10\% Asian, American Indian, or other ethnicity) and socioeconomic status. Students in social studies classes were invited to participate in the study, and those who received written parental consent and agreed to take part completed a packet of questionnaires during a regular class period. Most students received parental permission (> 80\%), but a small number were absent on the day the questionnaires were completed or chose not to participate, resulting in a final sample that included approximately $75 \%$ of the students in the classes. Most students completed the packets in 45 to 60 minutes.

\section{Measures}

\section{Romantic Attachment Style}

The Experiences in Close Relationships Scale (Brennan et al., 1998) was used to tap adolescents' working models of romantic relationships. It assesses beliefs and expectations about how others in romantic relationships will behave toward the respondent, and yields scores on two dimensions: anxiety and avoidance. The items on the 18-item Anxiety scale reflect respondents' tendency to worry about the status of the relationship and the availability of the partner (e.g., "I need a lot of reassurance that I am loved by my partner"), whereasthe18 items on the Avoidance scale are more behaviorally oriented, reflecting the needs and desires of the respondent to spend time with and be close to the partner ("I try to avoid getting too close to my partner"). Participants respond ona7-point scale ranging from 1 (disagree strongly) to 7(agree strongly). Alpha coefficients were .89 and .74 for the Anxiety and Avoidance scales, respectively.

\section{Dating Aggression}

The Conflict in Relationships scale (CIR; Wolfe, Reitzel-Jaffe, Gough, \& Wekerle, 1994) was used to assess coercive and aggressive behavior in dating relationships. The CIR was developed specifically for use with adolescents and includes milder forms of aggression that might be more common in teen dating relationships than adult relationships, as well as more severe examples of abuse. Perpetration of aggressive behavior is assessed with two scales: Negative Communication, which taps verbally or emotionally abusive behavior (e.g., insulting, ridiculing in front of others, using a hostile tone of voice); and Abuse/Coercion, which assesses physically aggressive behavior (e.g., hitting, kicking, destroying something of value). A third scale, Victimization, assesses aggressive or abusive behavior that participants' dating partners exhibited toward them. The CIR also includes a Sexual Aggression scale, but those items were omitted from the questionnaire used in this study at the request of the school, and consequently only the Negative Communication and Abuse/Coercion scales were analyzed. Coefficient alpha 
in this sample was commensurate with that reported by Wolfe et al. (1994): Negative Communication $=.88 ;$ Abuse/Coercion $=.83 ;$ Victimization $=.89$.

\section{Interparental Aggression}

The Conflict Tactics Scale (CTS; Straus, 1979) was used to assess adolescents' reports of the level of verbal and physical aggression exhibited by each of their parents toward the other. The CTS includes 15 behaviors, including "Raised voice or yelled at the other," "Pushed, grabbed, or shoved," and "Threatened with a knife or gun." Participants rated how frequently each behavior had occurred in the past year on a 7-point scale ranging from 0 (never) to 6 (more than 20 times). Scores on the verbal and physical aggression scales were summed for fathers and mothers separately, and then standardized. The CTS is a widely used measure of aggression in the family with strong psychometric characteristics; coefficient alpha in this sample was .91for reports of mothers' aggression and .88 for fathers.

\section{Parent-Child Aggression}

The version of the CTS developed to assess conflict in parent-child relationships was used. It includes the same structure and items as the measure of interparental aggression, but inquires about behaviors that have occurred between the child and each parent. The frequency that each behavior had occurred in the past year was rated on a 7-point scale ranging from 0 (never) to 6 (more than 20 times). Alpha coefficients were .89 for mother-child relationships and .87 for father-child relationships. Scores on the verbal and physical aggression scales were summed for father-child and mother-child relationships separately, and then standardized. Because we did not have specific hypotheses regarding the relative role of interparental and parent-child aggression in relation to the other constructs and these variables were significantly correlated, we combined the standard scores for the measures of interparental and parent-child aggression to form a composite measure of family aggression.

\section{Beliefs about Aggression}

Participants' beliefs about the justifiability of using aggression toward a dating partner were assessed with the Attitudes About Dating Index (AADI; Foo \& Margolin, 1995). The AADI presents respondents with a list of situations and asks them to indicate how justifiable it would be for a man or woman to slap or hit his or her girlfriend or boyfriend in those circumstances on a 7-point scale. The measure includes two subscales pertaining to two contexts that might provoke aggression: Self-Defense and Humiliation. Foo and Margolin found that only the Humiliation 
scale predicted dating aggression in a sample of college students, and so we used that scale as our measure of aggressive attitudes. The Humiliation scale includes items such as "your girl/boy friend makes you look like a fool in front of your friends" and "you learn that your boy/girlfriend is having an affair." Alpha coefficients on the Humiliation scale in this sample were .91 for boys' behavior and .94 for girls; on the Self-Defense scale, coefficient alpha was .69 for boys and .84 for girls.

\section{Anger Regulation}

Participants' tendency to experience and express anger was assessed with the Trait Anger Scale (TAS; Spielberger, Jacobs, Russel, \& Crane, 1983). This measure conceptualizes trait anger as a fairly stable individual characteristic distinct from respondents' current mood. It includes 15 items rated on a 4-point scale ranging from 1 (almost never) to 4 (almost always). Sample items include "I am quick tempered" and "When I get mad, I say nasty things." Coefficient alpha in this sample was .91.

\section{Results}

Prior studies suggest that the predictors of dating aggression are different for boys and girls, so we first conducted Box's M test to determine if the pattern of associations among the variables was similar for boys and girls. This analysis revealed a significant gender difference and consequently we conducted analyses separately for boys and girls, Box's $M=75.77, F(28$, $208,047)=2.63, p<.01$. Boys and girls also differed in mean levels of three variables. Girls reported engaging in higher levels of physical and verbal aggression toward their dating partners: for Abuse, $t(371)=2.40, p<.05$; for Negative Communication, $t(365)=2.77, p<.05$, and reported more accepting attitudes regarding aggression in romantic relationships, $t(356)=2.79$, $p<.05$. Rates of verbal and physical aggression in dating relationships were comparable to those reported in other high school samples (see Wekerle \& Wolfe, 1999): 21\% acknowledged that they insulted, ridiculed, or made fun of their partners in front of others; $18 \%$ reported that they had pushed, shoved, or shook their partners; and 25\% had hit, punched, or kicked a boyfriend or girlfriend. Means, standard deviations, and correlations among the variables are listed in Table1.

\section{Moderating the Link between Family Aggression and Dating Behavior}

The first set of analyses examined the role of the attachment dimensions of anxiety and avoidance in moderating the relation between family aggression and the three indexes of dating 
aggression (Negative Communication, Abuse/Coercion, Victimization). Each variable was centered prior to analyses, and product terms representing the interaction of family aggression with each attachment dimension were computed. Hierarchical regression analyses were conducted in which the measures of family aggression and both attachment dimensions were entered in the first step, and the three product terms were entered in the second step (seeTable2). Moderation is documented if the product term accounts for significant variance in the outcome measure (Baron\& Kenny, 1986). We present the analyses for boys' data first.

As Table 2 shows, for boys, neither anxiety nor avoidance was a unique predictor of abuse/coercion, negative communication, or victimization in dating relationships with family aggression in the equation. However, anxiety was a significant moderator of the association between exposure to aggression in the family and the perpetration of abusive behavior in dating relationships $(b=.30)$. To interpret this interaction, we examined the association between family aggression and dating abuse separately for youths who were1 $S D$ above and1 SD below the mean on the Anxiety sub-scale (Aiken \& West, 1991). Family aggression had a stronger relation with dating abuse for those who were more anxious $(b=.59)$ than those reporting lower levels of anxiety $(b=.36)$. Avoidant attachment did not moderate the relations between family aggression and any of the measures of dating aggression.

For girls, anxiety had a significant direct relation with the Negative Communication scale, which assesses verbal aggression and emotional abuse, and a marginally significant association with victimization. Girls reporting greater anxiety in regard to romantic relationships indicated that they engaged in more verbal aggression with their partners and were the recipient of greater aggression and abuse from their partners. There also was a marginally significant association between avoidance and abuse: Girls expressing greater discomfort with closeness reported engaging in lower levels of physical aggression. In contrast to the boys' data, avoidance rather than anxiety moderated the association between family aggression and perpetration of abuse $(b$ $=.28$ ). Examining the relations between family aggression and abusive behavior in dating relationships for girls high (+1 SD) and low (-1 SD) in avoidance showed that there was no association for girls low in avoidance $(b=.07)$, but for girls high in avoidance, greater exposure to aggression in the family was strongly associated with perpetration of abusive and coercive behavior toward their dating partners $(b=.67)$.

\section{Moderating the Link between Mediating Processes and Dating Behavior}

The second set of analyses examined whether attachment style might affect the relation between family and dating aggression by moderating the impact of cognitive and affective 
processes on dating behavior. We again conducted hierarchical regression analyses to test these possibilities (see Table 3). For boys, neither attachment dimension was uniquely related to any of the dating indexes; however, there was a significant mode rating effect between anxious attachment and aggressive attitudes in predicting dating abuse $(b=.21)$, and a marginally significant interaction effect between anxious attachment and anger regulation( $b=.14, p=.05)$. Specifically, the tendency to view aggression as more acceptable was a strong predictor of dating abuse for boys reporting high levels $(+1 S D)$ of anxiety $(b=.69)$ but was not associated with abuse for those exhibiting low levels $(-1 S D)$ of anxiety $(b=.00)$. Similarly, poor management of anger was closely related to dating abuse in highly anxious boys $(b=.52)$ but not in those with low anxiety $(b=.10)$. We also found one moderating effect of avoidance ( $b$ $=.18$ ): The relation between aggressive attitudes and abusive behavior was significant and positive for both groups, but it was stronger for boys who were highly avoidant $(b=.70)$ than those low in avoidance $(b=.50)$. There were no significant moderating relations found for negative communication or victimization.

Turning to the girls' data, anxious attachment uniquely predicted negative communication and victimization, and was a marginally significant predictor of abuse/coercion. Girls expressing higher levels of anxiety were more likely to report all three forms of aggression. We also found one significant interaction and one marginally significant involving working models and the mediating processes. First, avoidance moderated the association between attitudes about the justifiability of aggression and victimization $(b=-.18)$ : Girls who were low in avoidance showed a significant, positive association between these constructs $(b=.56)$, whereas those high in avoidance exhibited a negative but nonsignificant association $(b=-.21)$. The marginally significant interaction $(b=-.14, p<.07)$ reflected a similar pattern of relations in regard to perpetration of dating aggression: Girls low in avoidance exhibited a significant, positive relation between aggressive attitudes and dating aggression $(b=.45)$, whereas those high in avoidance had a nonsignificant, negative relation between aggressive attitudes and aggressive behavior $(b$ $=-.14)$.

\section{Discussion}

The goal of this study was to explore how experiences with aggression in the family lead to abusive behavior in dating relationships in adolescence. The data suggest that youths' romantic attachment style plays an important role in shaping the impact of family aggression on their behavior toward dating partners, and offer insight into the processes by which their expectations and beliefs about relationships interact with other factors shown to mediate the 
association between aggression in the family and dating contexts. The nature of the relations between attachment style and dating behavior differed for boys and girls, but for both, attachment generally was a stronger predictor of the perpetration of physical aggression than verbal aggression or emotional abuse. Given that these less severe forms of aggression are fairly common in teen dating relationships, individual differences in adolescents' working models might have diminished power to predict these aspects of dating behavior.

We first examined whether the dimensions of anxiety or avoidance in regard to romantic relationships moderated the association between family and dating aggression. Boys high in attachment anxiety exhibited a stronger relationship between aggression in the two contexts than did boys low in anxiety. For girls, avoidance was a significant moderator: Girls who were highly avoidant showed a strong positive association between experiences with interparental aggression and abusive behavior toward dating partners, whereas there was no association for girls low in avoidance. These results are largely consistent with Wekerle and Wolfe's (1998) finding that child maltreatment was more closely associated with dating aggression for boys with anxious or avoidant attachments than those with secure attachments.

We then investigated how attachment style functions in relation to family aggression by assessing its associations with two processes previously shown to mediate the impact of family experiences on dating behavior. Prior analyses of these data showed that both attitudes regarding the acceptability of aggression and the capability to regulate anger were unique and independent mediators of the association between exposure to aggression in the family and aggressive behavior in dating relationships (Kinsfogel \& Grych, 2004). For boys, the attachment dimensions did not directly predict any of the dating measures, but anxiety was a significant moderator of the relation between abusive or coercive behavior toward dating partners and both accepting attitudes toward aggression and anger regulation. The nature of these interactions was striking: For boys high in anxiety, associations between both mediators and dating aggression were strong and significant $(b s=.69, .52)$, but for boys reporting little attachment anxiety there was no association between either mediator and abusive behavior ( $b s=.00, .10)$. There was only one significant finding for boys' avoidance: All boys with anger regulation problems reported engaging in more abusive behavior, but this relationship was more pronounced for boys with avoidant styles.

The pattern of results differed for girls. First, anxiety predicted all forms of dating aggression, adding unique variance to that accounted for by attitudes about aggression and anger regulation. Girls who were more anxious about the status of their romantic relationships reported engaging in higher levels of verbal aggression and emotional abuse, marginally more 
physical aggression, and greater victimization. Second, avoidance rather than anxiety moderated the relations between aggressive attitudes and both the perpetration of abuse and victimization, although the former finding was only marginally significant. The finding that girls who were lower in avoidance showed stronger relations between aggressive attitudes and dating abuse appears to be at odds with the finding that avoidance is a risk factor for dating abuse. However, it might reflect the possibility that cognitions about aggression are more closely connected with behavior for girls who are more emotionally involved in a dating relationship. For girls who are avoidant of relationships, their beliefs about the justifiability of aggression simply might not have much influence relative to their more general tendency to avoid engagement.

These findings indicate that romantic attachment style acts as a risk or protective factor that can amplify or attenuate the impact of aggressive attitudes and problems with regulating anger. Although anxious girls were more likely to engage in verbally or emotionally abusive behavior and to report more victimization, in general attachment style did not directly predict physical aggression toward dating partners. Indeed, aggression is not a necessary consequence of either an anxious or avoidant attachment style. There are multiple ways for individuals to cope with worries about the availability and commitment of their partner or discomfort with emotional closeness that do not involve abusive behavior. For example, anxious youth might become excessively dependent or clingy, whereas avoidant adolescents might simply withdraw when a relationship becomes too emotionally intimate. However, for individuals who perceive aggression to be justifiable in close relationships, the data reported here suggest that the fear that their partners are not committed to the relationship or want to end it might lead them to engage in coercive or abusive behavior in an effort to maintain the relationship (see Volz \& Kerig, this issue). Aggression also might occur because anxious boys with poor regulatory abilities experience anger when they perceive the threat of rejection; their fear of losing the relationship might increase their emotional arousal beyond a point where they can effectively manage it.

Avoidant attachment interacted with attitudes about the justifiability of aggression, but not anger regulation. It is possible that avoidance results in an emotional distancing that reduces inhibition of aggressive impulses; that is, highly avoidant youths might lack the empathy for their partner that would otherwise prevent them from acting abusively. Alternatively, aggressive behavior might itself be a distancing strategy that keeps romantic relationships from being too emotionally intimate. Viewed from a more positive perspective, secure attachments might be a protective factor that interrupts the transmission of aggression from family to romantic relationships by reducing the potency of aggressive attitudes.

These findings offer a developmental perspective on Holtzworth-Monroe et al.'s (1997) 
research on attachment in violent men. They found that attachment-related constructs differentiated male batterers who were violent only toward their wives from those who exhibited violence across contexts and relationships. The "partner-only" batterers exhibited signs of anxious-insecure attachment: They worried about their partners rejecting them, were highly dependent on them, and quickly became jealous. In contrast, the batterers whose aggression was pervasive fit a more avoidant profile: They expressed low levels of dependency and fear of losing their partners and appeared more disengaged in the relationship. The data reported here suggest that links between relationship aggression and both attachment styles occur at an earlier developmental period and potentially set the stage for more severe forms of abuse later in life. Aggression is fairly common in adolescent romantic relationships but becomes less so in committed adult relationships; however, it is not clear which youths are at risk for developing more entrenched and severe forms of aggression in their intimate relationships and which are likely to develop healthier relationships as they enter adulthood. Attachment style might play an important role in the continuity of relationship aggression: When fears of rejection or discomfort with closeness lead to coercive or abusive behavior they are likely to hasten the end of the relationship, which in turn would further reinforce anxious or avoidant working models. The self-fulfilling nature of this cycle suggests that there is likely to be continuity in some individuals, but we know little about the stability of romantic attachment from adolescence to adulthood or about the factors that lead to change in youths' working models. Longitudinal research is needed to determine how attachment style relates to abusive behavior as individuals develop more lasting intimate relationships.

It also will be important to further explore the nature of gender differences in the links among family aggression, attachment, and romantic relationships. In addition to there being different (and fewer) significant moderating effects for girls, more of the variance in boys' behavior was accounted for in our analyses. The discrepancy was more pronounced for analyses involving attitudes about aggression and anger regulation. In these analyses, $41 \%$ of the variance in boys' coercive or abusive behavior was accounted for, compared to only $16 \%$ of the variance in girls' behavior. The difference can be attributed primarily to greater potency of family aggression, aggressive attitudes, and anger regulation as predictors of boys' behavior, because the magnitude of the beta weights for the interaction terms were very similar for boys and girls. These findings are consistent with prior research showing that experiences in the family are stronger predictors for dating aggression for boys than for girls, but reveal little about the source of the differences. Research examining other domains that could have a stronger influence on girls' aggressive behavior is needed. 
The results of this study suggest two additional directions for further investigation. First, examining youths' attachment styles in the context of their broader functioning and adjustment will provide a more complete understanding of the processes that guide their behavior with dating partners. In particular, witnessing violence in the home can lead to the development of posttraumatic stress disorder (PTSD), two of the hallmark symptoms of which are hyperarousal and avoidance of the stressor. Responses to trauma could interact in complex ways with the broader patterns of beliefs and expectations that children develop through interactions with their caregivers. For example, PTSD might intensify established tendencies toward anxiety and avoidance in romantic relationships, and avoidance in dating relationships could be a strategy for coping with the hyperarousal elicited in these contexts. Differentiating youths' working models of relationships from the sequelae of exposure to trauma and examining their unique and combined influences on behavior can provide important insights for theory development and clinical intervention.

Second, although the focus of this study was on understanding continuity in aggression from family to dating relationships, it is equally important to explore why some children from violent homes do not repeat patterns of abuse in their own romantic relationships. Our data suggest that a close and supportive relationship with at least one parent could enable youths to develop healthy relationships with dating partners, but the literature on resilience indicates that individual characteristics and experiences in other kinds of relationships also might be important (e.g., Masten et al., 1999). For example, adolescents who effectively regulate their affect and behavior might be better able to manage aggressive impulses and constructively resolve conflicts that arise in close relationships.

The results of this study should be interpreted in light of its methodological limitations. Most notably, all of the data were assessed via youth self-report, which has the potential to inflate associations among the constructs. Obtaining partner reports and observational data on interactions in romantic relationships will offer important perspectives on youths' behavior toward dating partners. A second limitation is that the data are cross-sectional and thus cannot address issues related to causation. Because attachment style is affected by the nature of individuals' relationships, it is not clear if youths' working models influence their behavior toward their partners or vice versa. Longitudinal research would provide the opportunity to more sensitively examine the interplay of attachment, attitudes, emotions, and behavior over time.

Despite these limitations, this study suggests that adolescents' working models are important for understanding the conditions under which beliefs about the justifiability of aggression and problems managing anger are likely to lead to dating abuse. Although we did not 
explicitly test attachment style as a mediating process, the regression analyses indicated that, with one exception, anxiety and avoidance did not uniquely predict the indexes of dating aggression and thus did not function as mediators. Taken together with other research that has failed to find support for attachment style as a mediator (Feiring et al., 2002; Levendosky et al., 2002), this study indicates that attachment style might be best understood as a risk or protective factor that can magnify or attenuate the impact of family experiences on adolescents' behavior in romantic relationships. A critical implication of this conclusion is that the transmission of aggression from family to dating relationships could be interrupted by fostering youths' attachment security. If at least one parent can remain attuned and responsive to the child despite other problems in the family, it could buffer the child from adverse effects of interparental and parent-child aggression. Further, because adolescents' working models of relationships also can be shaped by other close relationships, developing supportive relationships with other adults or peers also has the potential to promote healthy and satisfying romantic relationships.

\section{References}

Aiken, L. S., \& West, S. G. (1991). Multiple regression: Testing and interpreting interactions. Thousand Oaks, CA: Sage.

Baron, R. M., \& Kenny, D. A. (1986). The moderator-mediator variable distinction in social psychological research: Conceptual, strategic, and statistical considerations. Journal of Personality and Social Psychology, 51, 1173-1182.

Bowlby, J. (1969). Attachment and loss: Vol. 1. Attachment. London: Hogarth.

Brennan, K. A., Clark, C.L.,\& Shaver, P.R.(1998).Self-report measurement of adult attachment: An integrative overview. In J. A. Simpson \& W. S. Rholes (Eds.), Attachment theory and close relationships (pp. 46-76).New York: Guilford.

Collins, W. A., \& Sroufe, L. A. (1999). Capacity for intimate relationships: A developmental construction. In W. Furman, B. Brown, \& C. Feiring (Eds.), The development of romantic relationships in adolescence (pp. 235-265). Cambridge, UK: Cambridge University Press.

Connolly, J., Friedlander, L., Pepler, D., Craig, W., \& Laporte, L.(2010).The ecology of adolescent dating aggression: Attitudes, relationships, media use, and sociodemographic risk factors. Journal of Aggression, Maltreatment, and Trauma, 19(5), 469-491.

Davila, J., Steinberg, S.J., Kachadourian, L., Cobb, R., \& Fincham, F. (2004).Romantic involvement and depressive symptoms in early and late adolescence: The role of a preoccupied relational style. Personal Relations, 111, 161-178. 
Feiring, C., Deblinger, E., Hoch-Espada, A., \& Haworth, T. (2002). Romantic relationship aggression and attitudes in high school students: The role of gender, grade, and attachment and emotional styles. Journal of Youth and Adolescence, 31, 373-385.

Foo, L., \& Margolin, G. (1995). A multivariate investigation of dating aggression. Journal of Family Violence, 10, 351-377.

Fraley, R.C., \& Shaver, P.R. (2000).Adult romantic attachment: Theoretical developments, emerging controversies, and unanswered questions. Review of General Psychology, 4, 132-154.

Fraley, R. C., \& Waller, N. G. (1998). Adult attachment patterns: A test of the typological model. In J. A. Simpson \& W. S. Rholes (Eds.), Attachment theory and close relationships (pp. 77-114). New York: Guilford.

Furman, W., Simon, V. A., Shaffer, L., \& Bouchey, H. A. (2002).Adolescents' working models and styles for relationships with parents, friends, and romantic partners. Child Development, 73, 241-255.

Grych, J. H., Wachsmuth-Schlaefer, T., \& Klockow, L.L.(2002).Interparental aggression and young children's representations of family relationships. Journal of Family Psychology, 16, 259-272.

Hazan, C., \& Shaver, P.R.(1994).Attachment as an organizational framework for research on close relationships. Psychological Inquiry, 5, 1-22.

Holtzworth-Monroe, A., Stuart, G. L., \& Hutchinson, G. (1997). Violent vs. nonviolent husbands: Differences in attachment patterns, dependency, and jealousy. Journal of Family Psychology, 11, 314-331.

Kinsfogel, K., \& Grych, J. H. (2004). Interparental conflict and adolescent dating relationships: Integrating cognitive, emotional, and peer influences. Journal of Family Psychology, 18, $505-515$.

Levendosky, A.A., Huth-Bocks, A., \& Semel, M.A.(2002).Adolescent peer relationships and mental health functioning in families with domestic violence. Journal of Clinical Child and Adolescent Psychology, 31, 206-218.

Masten, A. S., Hubbard, J. J., Gest, S. D., Tellegen, A., Garmezy, N., \& Ramirez, M. (1999). Competence in the context of adversity: Pathways to resilience and maladaptation from childhood to late adolescence. Development and Psychopathology, 11, 143-169.

O'Leary, K. D., \& Cascardi, M. (1998). Physical aggression in marriage: A developmental analysis. In T. N. Bradbury (Ed.), The developmental course of marital dysfunction (pp. 343-374). Cambridge, UK: Cambridge University Press. 
Riggs, D. R., \& O'Leary, K.D. (1996). Aggression between heterosexual dating partners: An examination of a causal model of courtship aggression. Journal of Interpersonal Violence, 11, 519-540.

Shamir, H., Schudlich, T. D., \& Cummings, E. M. (2001). Marital conflict, parenting styles, and children's representations of family relationships. Parenting: Science and Practice, 1 , 123-151.

Spielberger, C.D., Jacobs, G., Russel, S.,\& Crane, R.S. (1983).Assessment of anger: The State-Trait Anger scale. In J.N. Butcher \& C.D. Spielberger (Eds.), Advances in personality assessment: Vol. 2 (pp. 159-187). Hillsdale, NJ: Lawrence Erlbaum Associates.

Steinberg, S.J., Davila, J., \& Fincham, F. (2006).Adolescent marital expectations and romantic experiences: Associations with perceptions about parental conflict and adolescent attachment security. Journal of Youth and Adolescence, 35, 333-348.

Straus, M.A. (1979). Measuring intrafamily conflict and violence: The Conflict Tactics (CT) Scales. Journal of Marriage and the Family, 41, 75-88.

Waters, E., \& Cummings, E. M. (2000). A secure base from which to explore relationships. Child Development, 71, 164-172.

Wekerle, C., \& Wolfe, D.A.(1998). The role of child maltreatment and attachment style in adolescent relationship violence. Development and Psychopathology, 10, 571-586.

Wekerle, C., \& Wolfe, D. A. (1999). Dating violence in mid-adolescence: Theory, significance, and emerging prevention initiatives. Clinical Psychology Review, 19, 435-456.

Wolfe, D. A., Reitzel-Jaffe, D., Gough, R., \& Wekerle, C. (1994).Conflicts in relationships: Measuring physical and sexual coercion among youth. Available from the Youth Relationships Project, Department of Psychology, The University of Western Ontario, London, Canada, N6A5C2. 


\section{Appendix}

Table 1: Means, Standard Deviations, and Correlations among Study Variables

\begin{tabular}{lcccccccccr}
\hline Variable & 1 & 2 & 3 & 4 & 5 & 6 & 7 & 8 & $M$ & $S D$ \\
\hline $\begin{array}{l}\text { 1. Dating abuse } \\
\text { 2. Dating negative }\end{array}$ & $.62^{*}$ & $.70^{*}$ & $.63^{*}$ & $.41^{*}$ & $.50^{*}$ & $.38^{*}$ & $.19^{*}$ & .13 & 2.36 & 4.46 \\
$\quad$ communication & & & $.79^{*}$ & $.28^{*}$ & $.37^{*}$ & $.37^{*}$ & $.21^{*}$ & .02 & 8.93 & 8.86 \\
$\begin{array}{l}\text { 3. Dating } \\
\quad \text { victimization }\end{array}$ & $.67^{*}$ & $.70^{*}$ & & $.44^{*}$ & $.37^{*}$ & $.42^{*}$ & $.22^{*}$ & .00 & 11.59 & 13.10 \\
$\begin{array}{l}\text { 4. Family aggression } \\
\text { 5. Aggressive }\end{array}$ & $.24^{*}$ & $.20^{*}$ & $.25^{*}$ & & $.35^{*}$ & $.46^{*}$ & $.27^{*}$ & .04 & 151.13 & 161.38 \\
$\quad$ attitudes & $.16^{*}$ & $.19^{*}$ & .14 & .07 & & $.32^{*}$ & $.20^{*}$ & $.18^{*}$ & 21.31 & 13.39 \\
6. Anger regulation & $.20^{*}$ & $.22^{*}$ & $.22^{*}$ & $.23^{*}$ & $.16^{*}$ & & $.29^{*}$ & .03 & 28.93 & 11.10 \\
7. Anxiety & $.17^{*}$ & $.27^{*}$ & $.26^{*}$ & .16 & .11 & $.22^{*}$ & & -.05 & 3.09 & 1.16 \\
8. Avoidance & .04 & .06 & .04 & .15 & .01 & .03 & .02 & & 3.14 & .97 \\
$M$ & 3.58 & 11.51 & 13.69 & 191.12 & 25.57 & 30.90 & 3.32 & 3.26 & & \\
$S D$ & 5.32 & 8.94 & 13.94 & 151.13 & 14.68 & 8.93 & 3.09 & 3.14 & & \\
\hline
\end{tabular}

Note. Values above the diagonal are for boys; values below the diagonal are for girls. * $p<.05$. 
Table 2: Moderator Analyses of Relations between Family and Dating Aggression

\begin{tabular}{|c|c|c|c|c|c|c|}
\hline & \multicolumn{2}{|c|}{ Abuse/coercion } & \multicolumn{2}{|c|}{$\begin{array}{c}\text { Negative } \\
\text { communication }\end{array}$} & \multicolumn{2}{|c|}{ Victimization } \\
\hline & $\beta$ & $R^{2}$ & $B$ & $R^{2}$ & $\beta$ & $R^{2}$ \\
\hline \multicolumn{7}{|l|}{ Boys } \\
\hline Step 1: Simple effects & & $.21^{* *}$ & & $.13^{*}$ & & $.24^{* *}$ \\
\hline Family aggression & $.41^{* *}$ & & $.30^{* *}$ & & $.46^{* *}$ & \\
\hline Anxious attachment & .13 & & .14 & & .09 & \\
\hline Avoidant attachment & .04 & & -.02 & & -.01 & \\
\hline Step 2: Interaction effects & & $.29^{* *}$ & & $.14^{*}$ & & $.25^{* *}$ \\
\hline $\begin{array}{l}\text { Family aggression } \times \\
\text { Anxious attachment }\end{array}$ & $.30^{*}$ & & .06 & & .13 & \\
\hline $\begin{array}{l}\text { Family aggression } \times \\
\text { Avoidant attachment }\end{array}$ & -.04 & & -.10 & & .02 & \\
\hline \multicolumn{7}{|l|}{ Girls } \\
\hline Step 1: Simple effects & & $.09^{* *}$ & & $.14^{* *}$ & & $.10^{* *}$ \\
\hline Family aggression & $.24^{*}$ & & $.19^{*}$ & & $.25^{*}$ & \\
\hline Anxious attachment & .10 & & $.26^{*}$ & & $.15^{+}$ & \\
\hline Avoidant attachment & $-.15+$ & & -.17 & & -.13 & \\
\hline Step 2: Interaction effects & & $.16^{* *}$ & & $.14^{* *}$ & & $.11^{* *}$ \\
\hline $\begin{array}{l}\text { Family aggression } \times \\
\text { Anxious attachment }\end{array}$ & -.07 & & -.06 & & -.06 & \\
\hline $\begin{array}{l}\text { Family aggression } \times \\
\text { Avoidant attachment }\end{array}$ & $.28^{* *}$ & & .02 & & .08 & \\
\hline
\end{tabular}

Note. Beta values are from step at entry.

${ }^{+} p<.10 .{ }^{*} p<.05 .{ }^{* *} p<.01$. 
Table 3: Moderator Analyses of Relations among Aggressive Attitudes, Anger

Regulation, and Dating Aggression

\begin{tabular}{|c|c|c|c|c|c|c|}
\hline & \multicolumn{2}{|c|}{ Abuse/Coercion } & \multicolumn{2}{|c|}{$\begin{array}{c}\text { Negative } \\
\text { communication }\end{array}$} & \multicolumn{2}{|c|}{ Victimization } \\
\hline & $\beta$ & $R^{2}$ & $B$ & $R^{2}$ & $\beta$ & $R^{2}$ \\
\hline \multicolumn{7}{|l|}{ Boys } \\
\hline Step 1: Simple effects & & $.32^{* *}$ & & $.23^{*}$ & & $.24^{* *}$ \\
\hline Aggressive attitudes & $.41^{* *}$ & & $.24^{* *}$ & & $.21^{* *}$ & \\
\hline Anger regulation & $.25^{* *}$ & & $.30^{* *}$ & & $.34^{* *}$ & \\
\hline Anxious attachment & .05 & & .12 & & .09 & \\
\hline Avoidant attachment & .07 & & .02 & & .00 & \\
\hline Step 2: Interaction effects & & $.44^{* *}$ & & $.25^{*}$ & & $.28^{* *}$ \\
\hline $\begin{array}{c}\text { Aggressive attitudes } \times \\
\text { Anxious Attachment }\end{array}$ & $.21^{* *}$ & & .02 & & .10 & \\
\hline $\begin{array}{l}\text { Anger regulation } \times \\
\text { Anxious attachment }\end{array}$ & $.14^{+}$ & & .12 & & .13 & \\
\hline $\begin{array}{l}\text { Aggressive attitudes } \times \\
\text { Avoidant attachment }\end{array}$ & $.18^{*}$ & & .06 & & .05 & \\
\hline $\begin{array}{l}\text { Anger regulation } \times \\
\text { Avoidant attachment }\end{array}$ & -.01 & & -.05 & & -.08 & \\
\hline \multicolumn{7}{|l|}{ Girls } \\
\hline Step 1: Simple effects & & $.08^{* *}$ & & $.15^{* *}$ & & $.11^{* *}$ \\
\hline Aggressive attitudes & $.14^{+}$ & & $.17^{*}$ & & .12 & \\
\hline Anger regulation & $.16^{*}$ & & $.17^{*}$ & & $.15^{*}$ & \\
\hline Anxious attachment & $-.12^{+}$ & & $.23^{* *}$ & & $.21^{*}$ & \\
\hline Avoidant attachment & -.04 & & -.06 & & -.03 & \\
\hline Step 2: Interaction effects & & $.10^{*}$ & & $.16^{* *}$ & & $.16^{* *}$ \\
\hline $\begin{array}{c}\text { Aggressive attitudes } \times \\
\text { Anxious attachment }\end{array}$ & .02 & & -.08 & & -.10 & \\
\hline $\begin{array}{l}\text { Anger regulation } \times \\
\text { Anxious attachment }\end{array}$ & .04 & & .01 & & -.05 & \\
\hline $\begin{array}{l}\text { Aggressive attitudes } \times \\
\text { Avoidant attachment }\end{array}$ & $-.14^{+}$ & & -.03 & & $-.18^{*}$ & \\
\hline $\begin{array}{l}\text { Anger regulation } \times \\
\text { Avoidant attachment }\end{array}$ & .03 & & -.03 & & .11 & \\
\hline
\end{tabular}

Note. Beta values are from step at entry.

${ }^{+} p<.10 .{ }^{*} p<.05 .{ }^{* \star} p<.01$. 